\title{
FORMAÇÃO DE PROFESSORES: UM OLHAR PARA A PRODUÇÃO DE TEXTO - DISCURSIVIDADE E INTENCIONALIDADE
}

\author{
Eliete Paes Landim Azevedo ${ }^{1}$ \\ Orientador Marco Aurélio Borges ${ }^{2}$ \\ MESTRADO EM CIÊNCIAS DA EDUCAÇÃO
}

\section{RESUMO}

Nossos alunos não estão em níveis esperados de leitura e escrita. Estamos em sala de aula com dificuldades em propor trabalhos com produção de textos orais e escritos, bem como para elaborar proposições, diagnósticos e intervenções. É necessário buscar a formação continuada com professores e pedagogos, objetivando a organização do trabalho que tenha como referência a realidade das crianças e sua formação humana, as experiências dos educandos e do professor com a leitura e escrita de produção de texto no cotidiano da escola. Uma das maiores dificuldades em relação a produções de textos pelos alunos se deve pela falta de objetivos claros e inadequações dos temas propostos, muitas vezes possuindo aspecto limitado, privilegiando somente alguns tipos e gêneros textuais, resultando em desconhecimento e insegurança por parte dos alunos. Entendendo a importância da formação continuada neste contexto, nos propomos a estudos que colaborem com a atribuição de sentido e consciência crítica ao longo do processo de ensinoaprendizagem dos professores e alunos, com intencionalidade de produções de textos orais e escritos aos alunos. Fornecendo subsídios a outros professores para implementação e vivências de práticas pedagógicas que considerem o discurso do aluno como razão de ser da produção textual. Tendo estes educandos interlocutores reais, definindo estratégias do discurso com conteúdo adequado a esses destinatários, visando práticas pedagógicas eficientes em partilhas de conversas e atividades de avaliação para o resultado em sua profissão de educador: o sucesso do aluno.

Palavras-chave: Formação do professor. Alfabetização. Escrita. Produção de texto. Séries Iniciais. Avaliação.

\footnotetext{
1 Atualmente é Professora efetiva de Séries Iniciais da Escola Estadual General Tibúrcio - SEDU - ES. Professora efetiva na Educação Infantil no CMEI Darcy Rodrigues Cardoso - PMC - ES. Tem experiência na área de Educação: Experiência em Formação Continuada na Educação de Jovens e Adultos e Professores de séries iniciais como Formadora; Contadora de histórias e Montagem Teatral; e Coordenadora de Turno. Especialização em Gestão Integradora e Arte-Educação. Mestranda em Educação.)

2 Graduado em Ciências Sociais, especialista em Psicopedagogia e Mestre em Cognição e Linguagem pela Universidade do Norte Fluminense Darcy Ribeiro - UENF Doutor em Ciências Humanas/Sociologia pelo Programa de Pós-Graduação em Sociologia e Antropologia da Universidade Federal do Rio de Janeiro (bolsista Cnpq).Pesquisador associado ao Núcleo de Pesquisas em Cidadania, Conflito e Violência Urbana, no âmbito da Universidade Federal do Rio de Janeiro. Período de bolsa de pósdoutorado na Universidade Estadual do Norte Fluminense Darcy Ribeiro.
} 
Lígia Martins lembra-nos da valorização necessária ao professor e essa valorização demanda reconhecer a formação e o trabalho desse, em toda a sua complexidade como fundamentalmente, condição para a plena humanização dos indivíduos, sejam eles educandos, sejam professores. Essa autora defende uma sólida formação, requerida pela complexidade das tarefas que o aguardam em sua atuação profissional (MARTINS, 2010).

"Embora tenha havido uma verdadeira revolução nesse campo nos últimos vinte anos, a formação ainda deixa muito a desejar" Nóvoa (2001). Segundo o autor as instituições ficam fechadas em si mesmas. É altamente necessário, para minimizar as lacunas, a continuidade da formação. Dessa forma, questiona-se: Como buscar nas teorias e nas pesquisas contribuições para a prática pedagógica? É possível inovar as estratégias de ensino ou mesmo utilizar das experiências já adquiridas com um novo olhar?

Vigorou em 5 de julho de 2012 através do Ministério da Educação a Portaria ํo - 867, de 4 de julho de 2012 onde foi instituído o PNAIC - Pacto Nacional pela Alfabetização na Idade Certa e suas ações do Pacto definindo as diretrizes gerais deste. O principal objetivo: garantir que todos os alunos do $1^{\circ}$ ao $3^{\circ}$ fossem alfabetizados. A formação continuada dos professores com Orientadores de Estudos e monitoramento da prática pedagógica nas escolas, uma das diretrizes gerais.

$\S 3^{\circ}$ As ações de formação serão conduzidas e monitoradas no âmbito dos estados, do Distrito Federal e dos municípios, reforçando a responsabilização das redes de ensino pelo desenvolvimento das atividades e resultados do Programa (BRASIL, 2012).

Fazendo parte na assessoria aos professores e pedagogos e na formação do Pacto Nacional pela Alfabetização na Idade Certa - PNAIC como Orientadora de estudos, percebemos com atividades e relatórios, que ainda há a predominância de ação pedagógica centrada na mecânica e na memória, pouco direcionada para a elaboração de sentidos e com pouco espaço para a vivência da criança no seu processo de construção do conhecimento. Dificuldades em propor trabalhos com produção de textos orais e escritos na sala de aula, elaborar proposições, diagnósticos e intervenções. 
Nossos alunos não estão em níveis esperados de leitura e escrita. No Espírito Santo $36,7 \%$ dos estudantes estão no Nível 3 de leitura. Conforme microdados do Saeb/ANA 2016/Inep. Nos incomoda saber que nossos alunos estão chegando ao término do ciclo de alfabetização sem ler e escrever.

"O Nível 3, além da compreensão geral de textos mais longos e complexos, concentra habilidades que requerem relacionar várias informações contidas no texto e um maior nível inferencial, tais como inferir sentido de expressão ou palavras e assunto em textos verbais e não verbais".

Estamos no SAEB com $66,4 \%$ dos estudantes no Nível 4 de leitura.

\begin{abstract}
No Nível 4 os estudantes provavelmente escrevem as palavras apresentadas corretamente, independentemente de sua complexidade, e atendem à proposta de construir uma narrativa, embora ainda possam incorrer em desvios que comprometem parcialmente o sentido desta. É preciso atenção ao fato de que $25,1 \%$ dos estudantes estão concentrados nos níveis 1,2 e 3 , que compreendem desde aqueles que ainda não escrevem palavras ou as escrevem de forma incompreensível até os estudantes que produzem textos com desvios que comprometem sua compreensão (INEP, 2016).
\end{abstract}

De acordo com Geraldi (2003), o texto deve ser o ponto de partida e ponto de chegada para o ensino da língua por que é nele que a língua se revela como forma (aspectos linguísticos) e como discurso.

Sustentados nos estudos de Gontijo e Schwartz (2008) que consideram a leitura e a escrita como uma prática sociocultural, busca-se compreender a necessidade da escrita em nossa sociedade, pois hoje o domínio da leitura e escrita são necessidades de sobrevivência.

Nossa proposta de investigação é buscar a formação de um grupo com professores e pedagogos para a realização de estudos na escola, objetivando a organização do trabalho que tenha como referência a realidade das crianças e sua formação humana, as experiências dos educandos e do professor com a leitura e escrita de produção de texto no cotidiano da escola, para que se coloquem como locutores em potencial.

Entendendo a importância da formação continuada neste contexto nos propomos a estudos que colaborem com a atribuição de sentido e consciência crítica ao longo do processo de ensino-aprendizagem dos professores e alunos, com intencionalidade de 
propor produções de textos orais e escritos aos alunos em sala de aula, fornecendo subsídios a outros professores para implementação e vivências de práticas pedagógicas que considerem o discurso do aluno como razão de ser da produção textual.

GONTIJO (2007) ressalta que, por meio dos textos, com objetivos e destinatários de fato, podemos ajudar as crianças a refletirem sobre a língua e fazer uso dos conhecimentos sobre o sistema de escrita que estão sendo apreendidos.

O professor precisa manter-se atualizado sobre as novas metodologias de ensino e desenvolver práticas pedagógicas mais eficientes, práticas essas que são alguns dos principais desafios da profissão de educador (NÓVOA, 2001). Dessa forma, questiona-se: como auxiliar o professor por meio de uma formação continuada, considerando o seu "saber" e a sua prática profissional, a compreender que o seu trabalho com produção de textos orais e escritos pode ser modificado, melhorado, reconstruído ou abandonado, tendo o seu cotidiano como referência? Como provocar reflexão sobre a língua e fazer uso dos conhecimentos sobre o sistema de escrita por meio da produção textual do/no aluno? Seria possível criar estratégias para incentivar a produção de texto do aluno com situações próximas do real para que ocorram as condições de produção, para que os textos produzidos na escola deixem de ser condenados ao artificialismo?

Para Geraldi, 2003, o diálogo na sala de aula, faz do aluno um interlocutor que não seja aquele cuja resposta poderá suprir a falta de conhecimento desejado, mas a pergunta é de quem já sabe o resultado: a professora. A resposta do aluno é mera "candidata" a resposta certa. Quem perguntou avalia a resposta conforme o poder de avaliador. As contribuições do aluno são sempre desclassificadas. Um ensino de conhecimento com a produção de texto seria recuperando professor e alunos como sujeitos que querem conhecer, que se compartilham na sala de aula. A atitude em relação ao conhecimento é o que muda as respostas. A formação é a própria vida.

Tendo o texto como o ponto de partida e ponto de chegada para o ensino da língua (Geraldi, 2003), apresentamos como objetivo geral fornecer em formação continuada subsídios para a construção de atividades de ensino para a produção de textos orais e escritos, por meio de estudo/prática entre um grupo de professores, tendo o aluno 
um interlocutor real em condições de definir as estratégias do discurso com conteúdo adequado a esse destinatário. É a produção de texto no processo de leitura e escrita.

\section{METODOLOGIA}

A opção metodológica para a pesquisa de estudo abordada é a "pesquisa qualitativa" que segundo LUDKE (1986, p.44) tem como características:

\footnotetext{
"A pesquisa qualitativa tem o ambiente natural como sua fonte direta de dados e o pesquisador como seu principal instrumento; os dados coletados são predominantemente descritivos; a preocupação com o processo é muito maior do que com o produto; o significado que as pessoas dão às coisas e à sua vida são focos de atenção especial pelo pesquisador; a análise dos dados tende a seguir um processo indutivo".
}

Os sujeitos dessa pesquisa serão os educandos, professores e pedagogos de uma escola pública, que oferte o ciclo de alfabetização. Baseada nas características da pesquisa qualitativa e na parceria com os professores regentes e pedagogos, será oferecida uma formação continuada, visando contribuir nos planejamentos e nas ações pedagógicas de sala de aula, considerando a necessidade de implementação de práticas reais de produção de textos. Contendo ações como reflexão em grupo sobre a concepção de cada um no trabalho de alfabetização dos educandos, organização de elementos que caracterizam a produção textual em nossa sociedade, verificando a presença ou não, em práticas com os alunos em sala de aula. Análise da importância da abordagem da leitura e produção de textos para conhecimentos sobre o nosso sistema de escrita. Compreensão de concepções de alfabetização na perspectiva da discursividade, sistematização de aportes teóricos que possam orientar as ações de mediação para intervir na produção de texto do aluno sem desprestigiá-lo ou desanimá-lo na busca da aquisição da escrita ortográfica.

Importante também o registro de necessidades de aprendizagem em instrumento próprio para ser socializado entre os pares em próximo encontro a partir das produções textuais realizadas pelas crianças com criação de estratégias e dinâmicas de propostas para produção de textos orais e escritos. Revisão de literatura para parâmetros teóricos, debates e questionários de autoavaliação da prática. Relatos exitosos ou não das sequências didáticas elaboradas no grupo. Audição de vídeos 
com entrevistas, cenas de sala de aula para o aprofundamento de debates relativos a diferentes temáticas propostas na formação.

A partir da escuta e do trabalho dos envolvidos em cada encontro, pode-se planejar e replanejar os próximos encontros, tendo como perspectiva e referência as necessidades e desejos dos professores e educandos. Segundo Nóvoa,

\footnotetext{
"Nas formações, o docente deve ser estimulado a trabalhar, a comunicar-se por meio de atividades em grupo, exercitando a troca de turnos entre os pares, a argumentação e, sobretudo, a intervenção com colegas e com alunos. Esse exercício pode contribuir tanto para o desenvolvimento profissional como pessoal" (acesso em outubro de 2015).
}

As ações serão registradas e gravadas para estudos em diferentes momentos durante a pesquisa, que terá variados momentos de reflexão-ação-reflexão, para a produção de conhecimento que nos auxiliem a compartilhar respostas. As reflexões realizadas bem como os dados coletados no período da pesquisa serão analisadas à luz do referencial teórico deste projeto, além de outros que surgirão, para a construção de práticas pedagógicas reflexivas no trabalho cotidiano das escolas.

Encontro com pedagoga e professores:

- Reflexão sobre a concepção de cada um no trabalho de alfabetização dos educandos

- Concepções de alfabetização na perspectiva da discursividade

- Análise sobre a importância da leitura e produção de textos para conhecimentos sobre o nosso sistema de escrita;

- Conversa sobre práticas exitosas de produção de texto.

- Registro de necessidades de aprendizagem a partir das produções textuais realizadas pelas crianças.

- Verificação da presença de textos utilizados pela sociedade, em práticas com os alunos em sala de aula.

- Verificação e reflexão sobre os destinatários previstos para a produção textual na sala de aula.

- Sistematização de aportes teóricos para ações de intervenção positiva na produção de texto do aluno.

- socialização das produções textuais realizadas pelas crianças em cada encontro. 
- Criação de estratégias e dinâmicas com propostas para produção de textos orais e escritos com destinatários pertinentes ao gênero textual produzido, como por exemplo: "O que é o que é?", "Quem sou eu?", "Complete a história”, Texto dramático, Questionário de dados pessoais...

- Avaliação e autoavaliação.

\title{
3. REFERENCIAL TEÓRICO
}

De uma maneira geral e social, a escrita é utilizada por muitas maneiras e variados objetivos. Para GERALDI (2003, p.160), existem condições necessárias para a produção de texto:
a) se tenha o que dizer;
b) se tenha uma razão para dizer o que se tem a dizer;
c) se tenha para quem dizer o que se tem a dizer;
d) o locutor se constitua como tal, enquanto sujeito que diz o que diz para quem diz;
e) se escolham as estratégias para realizar (a), (b), (c) e (d).

Por meio das palavras de Geraldi, compreende-se a linguagem como forma de interação que vai além do ato de escrever e ler. Envolve atores comunicativos em um contexto social e cultural em que o locutor e interlocutor vivem.

Para Backtim, (1997, p. 280) os textos produzidos são abordados de acordo com a proposta dos gêneros textuais.

\begin{abstract}
O emprego da língua efetua-se em forma de enunciados (orais e escritos) concretos e únicos, proferidos pelos integrantes desse ou daquele campo da atividade humana. Esses enunciados refletem as condições específicas e as finalidades de cada referido campo não só pelo conteúdo (temático) e pelo estilo da linguagem, ou seja, pela seleção dos recursos lexicais, fraseológicos e gramaticais da língua, mas, acima de tudo, por sua construção composicional. Todos esses três elementos - o conteúdo temático, o estilo, a construção composicional - estão indissoluvelmente ligados no todo do enunciado e são igualmente determinados pela especificidade de um determinado campo de ação. Evidentemente, cada enunciado particular é individual, mas cada campo de utilização da língua elabora seus tipos relativamente estáveis de enunciados, os quais denominamos gêneros do discurso. (BAKHTIN, 1997, p. 261).
\end{abstract}

As propostas de produção de texto elaboradas pelo professor, quando assume esta concepção, permite ao aluno saber qual papel deve exercer e de que forma ele pode 
permitir a participação do receptor da mensagem ou leitor do seu texto. Assim, o aluno tem consciência de elementos essenciais para a escrita de um bom texto como quem vai escrever o texto, quem vai receber o texto, qual o propósito do texto, qual gênero será escrito...

Para GONTIJO a prática de produção de textos orais convive com a prática de textos escritos para que os estudantes assumam-se como sujeitos e sejam motivados a falar e escrever sobre suas experiências, tenham interlocutores para seus textos, e considerando o que têm a dizer aos seus destinatários, escolher as melhores estratégias para compor seus textos. Por meio dos textos, podemos ajudar as crianças a refletirem sobre a língua e conhecimentos sobre o sistema de escrita. (2007).

Por isso, vale refletir com os próprios professores sua prática, construindo atividades de ensino para a produção de textos orais e escritos por meio de estudos e práticas entre um grupo de alunos, tendo estes educandos interlocutores reais, definindo estratégias do discurso com conteúdo adequado a esses destinatários.

Para criação de textos em variados gêneros textuais, como em convites, cartazes e banners para serem lidos de maneira real e atraente, pode ser interessante, ouvir, ler e preparar textos dramáticos através da história lida. As crianças vão se encantando em ouvir histórias do mesmo modo como as de antigamente como relata Glória Kirinus no prefácio, na orelha do livro Contar e Encantar de Cléo Busatto, 2017:

Cumulativa voz, de milenar encanto, que nasce do ventre da roda, atravessa auditórios, oficinas, cursos de comovidos ouvintes e hoje acompanha a nova espiral do próprio prazer, virando letra viva, inquieta e bem articulada. Cléo Busatto convida outras vozes para pensar com ela o mistério das metáforas que surpreendem o próprio mito e, assim, levanta significados densos nos enigmas que perseguem a origem de nossa humanidade.

Após ouvirem e lerem as histórias, as crianças farão seu texto coletivamente ou individualmente para atuarem como ator ou contrarregra e ainda poderão propagar sua apresentação através de convites e banners. Esta é apenas uma das possíveis estratégias próximas da necessidade real da escrita dentro da sala de aula

$\mathrm{Na}$ abordagem histórico-cultural o ensino da língua se forma na medida em que só o texto permite compreender como a língua se realiza enquanto forma e discurso. $A$ alfabetização é também um processo de produção de sentidos por meio do trabalho de leitura e da escrita. Então, ler e escrever são atividades por meio das quais as 
crianças podem expor para os outros e para si mesma o que pensam, sentem, desejam, gostam, concordam, discordam etc. Nesse sentido, a interação com o outro, por meio da leitura e da escrita é um processo dialógico desde o início. (GONTIJO, 2008). É a escrita como discurso que fundamenta a teoria histórico-cultural em que ensinar a língua é preconizar a produção de textos na medida em que só ele permite compreender a língua como emergente das interações sociais.

Com este aspecto de textos entendemos que de fato a alfabetização é baseada na concepção discursiva da leitura que segundo Gontijo é:

[...] como uma prática sociocultural em que se desenvolve a formação da consciência crítica, as capacidades de produção de textos orais e escritos, a leitura, os conhecimentos sobre o sistema de escrita da língua portuguesa, incluindo a compreensão das relações entre sons e letras e letras e sons (GONTIJO, 2008 p.15)

Para Steban e Zaccur não faltam pesquisas de denúncia e anúncio, não faltam intervenções realizadas. A professora da escola básica pode utilizar a parceria na produção da mudança no interior da escola. Não há como pensar a mudança sem a participação dos que vão construí-la no cotidiano da escola: professor e aluno. Precisamos dar ao aprofundamento teórico o sentido de buscas de respostas, que se transformam em novas perguntas caminhando para desestruturar o senso comum, surgindo assim uma professora-pesquisadora que discute sobre o processo de ensino-aprendizagem no espaço de aprendizagem, vendo mais profundamente suas questões. (ZACCUR, 2002).

Nóvoa, 2001 diz que o professor tem um "saber" dentro de si que é refletido em sua prática, mas precisa manter-se atualizado sobre as novas metodologias de ensino e desenvolver práticas pedagógicas mais eficientes, práticas essas que são alguns dos principais desafios da profissão de educador (NÓVOA, 2001).

O trabalho com leitura, escrita e produção de textos pode ser modificado, melhorado, reconstruído ou abandonado, refletindo sobre a língua e usos dos conhecimentos sobre o sistema de escrita. Criando incentivos para a produção de texto do aluno com situações próximas do real para que ocorram condições de produção, separadas do artificialismo. 


\section{CONSIDERAÇÕES FINAIS}

Uma das maiores dificuldades em relação a produções de textos pelos alunos se deve pela falta de objetivos claros nas propostas e inadequações dos temas propostos, muitas vezes possuindo aspecto limitado, privilegiando somente alguns tipos e gêneros textuais, resultando em desconhecimento e insegurança por parte dos alunos.

É preciso ir muito mais do que um determinado gênero textual. Segundo BUTZGE e CASAGRANDE em seu artigo Autoria e Leitor: O Processo de Produção Textual no Projeto "Comunica Realeza" (acesso em janeiro, 2020), citando indiretamente BRITO e $\mathrm{KOCH}$ :

mas considerar aspectos contextuais da produção, a fim de que o texto seja entendido como uma prática social e não, simplesmente, uma tarefa, uma redação, algo artificial, mera atividade escolar, da qual o real destinatário é o professor (BRITTO, 1997). Koch (2002, p. 55) lembra que Schnewly "entende o domínio (maestria) do gênero como o próprio domínio da situação comunicativa, domínio este que se pode dar através do ensino das capacidades de linguagem, isto é, pelo ensino das aptidões exigidas para a produção de um gênero determinado." Koch (2002) alerta para essa difícil apropriação dos gêneros textuais como conteúdo de ensino. Para a autora, com base em argumentos de Rojo, há nas escolas gêneros escolares e gêneros escolarizados, ou seja, muitos gêneros são próprios da esfera escolar, como o gênero "aula", e outros apropriados de outras esferas comunicativas para o ensino de aspectos da língua, como o gênero "dissertação", o qual inexiste fora dos muros das escolas.

Entendemos que estamos na fronteira que foge à artificialização do texto como nos advertiu Geraldi quando falou das condições de produção textual (2003).

Poderá surgir uma coletânea de estratégias de ensino elaboradas e vivenciadas com os professores e alunos, além da coletividade do grupo na formação, propondo produções de textos com sentido relevante orais e escritos em sala de aula, fornecendo subsídios até a outros professores para implementação e vivências de práticas pedagógicas.

Portanto a formação de professor mencionada por Nóvoa (2001) precisa entender e valorizar o saber que o professor tem dentro de si evidenciado em sua prática. Isso pode ser realidade em nossas reuniões com o grupo, visando práticas pedagógicas eficientes em partilhas de conversas e atividades para o resultado em sua profissão de educador: o sucesso do aluno. 


\section{REFERÊNCIAS}

BAKTHIN, Mikhail. Estética da criação verbal. São Paulo: Martins Fontes, 1997.

BRASIL. Ministério da Educação. Secretaria da Educação Básica. Formação de Professores no Pacto Nacional pela Alfabetização na Idade Certa. Brasília: MEC/SEB, 2012. Acesso em julho de 2019.

. Portaria № 867, de 4 de julho de 2012. Institui o Pacto Nacional pela Alfabetização na Idade Certa e as ações do Pacto e define suas diretrizes gerais. Diário Oficial da União, № 129, quinta-feira, 5 de julho de 2012, p. 22-23.

BUSATTO, Cléo. Contar e encantar - Pequenos segredos da narrativa. Petrópolis, RJ: Vozes, 2012.

BUTZGE, Clóvis Alencar: Sabrina CASAGRANDE - Autoria e Leitor: O Processo de Produção Textual no Projeto "Comunica Realeza" - Anais do SIELP. Volume 2, Número 1. Uberlândia: EDUFU, 2012. ISSN 2237-8758. http://www.ileel.ufu.br/anaisdosielp/wpcontent/uploads/2014/06/volume 2 artigo 078.pdf acesso em janeiro 2020.

DAEB, Diretoria de Avaliação da Educação Básica, Relatório SAEB/ANA Panorama do Brasil e dos Estados. Acesso em julho de 2019.

file:///D:/Documents/2020/RELATÓRIO\%20SAEBANA\%202016\%20PANORAMA\%2 0DO\%20BRASIL\%20E\%20DOS\%20ESTADOS.pdf

ESTEBAN, Maria Tereza e BACCUR, Edwiges (orgs.), Professora Pesquisadora uma práxis em construção. Rio de Janeiro: DP\&A, 2002.

GERALDI, João Wanderley. A Leitura na Sala de Aula As Muitas Faces de Um Leitor http://www.crmariocovas.sp.gov.br/pdf/ideias 05 p079-084 c.pdf

Portos de Passagem. 4. ed. São Paulo: Martins Fontes, 2003.

GONTIJO, Cláudia Maria Mendes. Alfabetização: a criança e a linguagem escrita. Campinas: Autores associados, 2007. 
Cláudia Maria Mendes; SCHWARTZ, Cleonara Maria. Alfabetização: teoria e prática. Curitiba, PR: Sol, 2008.

INEP. Censo Escolar da Educação Básica. Notas estatísticas, acesso em maio,2017 http://download.inep.gov.br/educacao basica/censo escolar/notas estatisticas/2017/n otas estatisticas censo escolar da educacao basica 2016.pdf)

LUDKE, Menga; ANDRE, Marli. Pesquisa em educação: abordagens qualitativas. São Paulo: EPU, 1986

MARTINS, LM., and DUARTE, N., orgs. Formação de professores: limites contemporâneos e alternativas necessárias [online]. São Paulo: Editora UNESP; São Paulo: Cultura Acadêmica, 2010. 191 p. ISBN 978-85-7983-103-4. Available from SciELO Books <http://books.scielo.org>.

MINAYO, Maria Cecília de Souza (org.); DESLANDES, Suely Ferreira; GOMES, Romeu. Pesquisa Social: Teoria, método e criatividade. Petrópolis: 2010

NÓVOA, Antonio. Professor se forma na escola. Revista Escola, 2001. Disponível em <http://revistaescola.abril.com.br/formacao/formacao-continuada/professor-se-formaescola-423256.shtml>. Acesso em outubro, 2018.

Portal do Professor. Edição 109 - Prêmio Vivaleitura - 7ª Edição. Acesso em junho, 2019.http://portaldoprofessor.mec.gov.br/noticias.html?idEdicao=124\&idCategoria=4 SCHWARTZ, Cleonara Maria. O trabalho com sequências didáticas, 2008. Mimeo. 